\begin{tabular}{|l|l|}
\hline Postprint Version & 1.0 \\
\hline Journal website & $\underline{\mathrm{http}: / / \text { www.ingentaconnect.com }}$ \\
\hline Pubmed link & $\begin{array}{l}\text { http://www.ncbi.nlm.nih.gov/entrez/query.fcgi? cmd=Retrieve\&db=pubmed\&dop } \\
\mathrm{t}=\text { Abstract\&list_uids=11386405\&query_hl=58\&itool=pubmed_docsum }\end{array}$ \\
\hline DOI & \multicolumn{2}{|l}{}
\end{tabular}

\title{
Muscle strength, pain and disability in patients with osteoarthritis
}

\author{
MARTIJN PM STEULTJENS ${ }^{1}$, JOOST DEKKER ${ }^{2}$, MARGRIET E VAN BAAR ${ }^{1}$, ROB AB OOSTENDORP $^{3}$ AND \\ JOHANNES WJ BIJLSMA ${ }^{4}$
}

${ }^{1}$ Netherlands Institute for Health Services Research, Utrecht

${ }^{2}$ Institute for Research in Extramural Medicine, Vrije Universiteit, Amsterdam and Institute for Health Services Research, Utrecht

${ }^{3}$ Netherlands Institute for Allied Health Professions, Amersfoort, The Netherlands and Faculty of Medicine and Pharmacology, Free University of Brussels, Brussels, Belgium

${ }^{4}$ Department of Rheumatology, Utrecht University Hospital, Utrecht, The Netherlands

Address for correspondence: Martijn PM Steultjens, Netherlands Institute of Primary Health Care

(NIVEL), PO Box 1568, 3500 BN Utrecht, The Netherlands. e-mail: m.steultjens@nivel.nl

Objective: Reduced muscle strength is regarded as a risk factor for pain and disability in osteoarthritis (OA). Currently, various indices for muscle strength are used when assessing determinants of pain and disability. The goal of the present study was to evaluate these indices of muscle strength.

Design: Isometric muscle strength was measured for 16 muscle actions around the knees and hips in 52 patients with OA of the hip and 70 patients with OA of the knee. Various indices of muscle strength were derived from these measurements, applying five alternative approaches. These approaches ranged from a single overall index to a set of 16 separate indices. The internal consistency of these indices was determined (Cronbach's $\alpha$ ), and it was determined to what extent they could reveal the association between reduced muscle strength on the one hand and pain and disability on the other hand.

Results: Internal consistency was satisfactory for all indices (Cronbach's $\alpha>0.74$ ). As expected, reduced muscle strength was associated with increased disability, but no clear relationship could be established between muscle weakness and pain. The strength of these associations did not depend on the approach used to derive the indices for muscle strength.

Conclusions: The indices did not show major differences with regard to internal consistency or the extent to which the association with pain and disability could be revealed. For reasons of parsimony, approaches resulting in few indices appear to be most useful. However, muscle strength was found to be significantly reduced around affected joints, compared with muscle strength around unaffected joints. Therefore, the most suitable approach for reducing muscle strength data into indices is one that results in as few indices as possible, but with separate indices for muscle strength around affected and unaffected joints. 


\section{INTRODUCTION}

Reduced muscle strength is frequently observed in patients with osteoarthritis (OA) of the hip or knee ${ }^{1-6}$ Loss of muscle strength is an important determinant of pain and disability in patients with OA. ${ }^{7-11}$ In the treatment of OA, especially in exercise therapy, improving muscle strength is regarded one of the most important mechanisms towards reducing pain and disability. ${ }^{12,13}$ Therefore, in research into the effectiveness of various treatments for OA, muscle strength is often chosen as one of the outcome measures.

The assessment of muscle strength involves measurement of a multitude of muscle actions at a number of anatomical sites (i.e. different joints). The large amount of data resulting from these measurements usually has to be reduced into one or more indices (sum scores). A number of different approaches to the calculation of indices can be chosen. These approaches differ in their level of reduction, from an approach where the measurements of all different muscle actions are reduced into one overall index for muscle strength, to an approach where no data reduction is performed and every muscle action is used as a separate index for muscle strength. Approaches that result in a large number of indices have the advantage that due to their high level of detail they may reveal relationships that would otherwise be obscured. On the other hand, such a level of detail can also result in an unnecessary number of indices. This could lead to results that are difficult to interpret. So, a level of detail needs to be maintained that prevents the loss of vital information, while at the same time a low number of indices is advantageous for ease of use and interpretation of results.

Thus, the question arises whether the way in which data are reduced into indices affects the observed relationship between muscle strength and pain and disability. The goal of the present study was to determine which approach to the reduction of data into indices for muscle strength would provide the optimal trade-off between parsimony (as few indices as possible) and detail (no loss of vital information). To this aim, first the internal consistency of the indices resulting from various approaches was determined. Second, the relationship was assessed between the indices of muscle strength on the one hand and pain and disability on the other hand. The relationship between muscle weakness and both pain and disability in OA has been well established. ${ }^{9,14,15}$ An index, or indices, for muscle strength should be able to accurately reveal the existence of these relationships. Thus, it was determined to what extent these indices could reveal the association between muscle strength on the one hand and pain and disability on the other.

\section{METHODS}

\section{Subjects}

Data were obtained from a randomized clinical trial into the effectiveness of exercise therapy in patients with OA of the hip or knee. ${ }^{16}$ Patients were included if they were diagnosed to have OA of the hip or knee according to the clinical classification criteria of the American College of Rheumatology. ${ }^{17,18}$ Two hundred patients participated in the trial. These were mainly patients with relatively mild symptoms of OA. For the present study, data were only used from patients diagnosed with either OA of one knee or OA of one hip. Patients diagnosed with OA at more than one site were excluded. This resulted in 122 patients in the analyses, 70 patients with unilateral knee OA and 52 patients with unilateral hip OA. Data for the present study were obtained at the onset of the trial (baseline).

\section{Muscle strength}

Isometric muscle strength was measured with a hand-held dynamometer, ${ }^{19}$ the MicroFet (Hoggan Health Industries, Draper, Utah). Hand-held dynamometry has been shown to be a reliable method of assessing muscle strength, ${ }^{20-23}$ and the dynamometer has the advantage of being small and easy to use. Make tests or 'doctor initiated' methods, ${ }^{21}$ were used. This means that the research assistant holds the dynamometer steady, while the patient exerts maximum force against it. ${ }^{24}$ After one initial attempt, during which the patient could get used to the required movement, patients were asked to build their effort to a maximum in the first 2 seconds of the test, and then to maintain this maximum force for 3 seconds. The peak force registered during those 3 seconds was recorded as the patient's maximum force. Muscle strength in newton's $(\mathrm{N})$ was measured bilaterally for eight muscle actions: flexion, extension, external rotation, internal rotation, abduction and adduction of the hip, and flexion and 


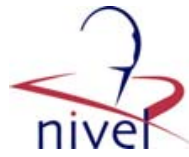

extension of the knee. Each muscle action was measured once. All muscle strength tests were performed within one session. During this session, other physical examinations were also carried out. This provided sufficient time between the muscle strength tests to avoid fatigue in the patients. During the tests, no fatigue or excessive pain (i.e. more pain than normal) was present as assessed by the patients themselves.

Starting positions were analogous to those used by Kendall et al. ${ }^{25}$ The protocol of Kendall et al. provides starting positions for both patient and therapist, and also prescribes the positioning of the dynamometer. In case a patient is unable to adopt a prescribed position, the protocol also provides an alternative position.

The tests were carried out by two experienced physical therapists. Prior to the trial, the interrater reliability was established using 10 healthy subjects and 10 patients with OA. The inter-rater reliability was satisfactory for all muscle actions (Pearson's $r$ exceeding 0.75 for all actions).

These measurements resulted in 16 items for muscle strength: 8 actions, both left and right. First, these measurements were corrected for body mass by dividing them by the patient's weight. After that, for all 16 items z-scores were computed to exclude problems due to different score ranges between items. A distinction was made between affected and unaffected joints (e.g. Z-scores were computed for flexion of the affected knee and the unaffected knee). For patients with hip OA, a distinction for the knees was made between knees ipsilateral and contralateral to the affected hip. Likewise, for knee OA patients, hips were divided into ipsilateral and contralateral to the affected knee.

A number of different approaches was chosen to compute indices for muscle strength. These were:

- Patient-based approach: One index; all 16 items added up to obtain a single index for muscle strength.

- Averaged joint approach: Two indices; a separate index was computed for muscle strength around the knee (comprising four items: flexion and extension for both the affected and unaffected knee), and for muscle strength around the hip (comprising 12 items: all six muscle actions for both the affected and unaffected hip).

- Single joint approach: Four indices; separate indices were made for the affected knee, unaffected knee, affected hip and unaffected hip. The knee indices consisted of two items each, while the hip indices had six items each.

- Averaged muscle action approach: Eight indices; they were made for each action by adding up the same action for the affected and unaffected joint (e.g. flexion of the affected hip and unaffected hip were added up to obtain a score for flexion of the hip). This resulted in separate indices for flexion, extension, external rotation, internal rotation, abduction and adduction of the hip, and flexion and extension of the knee.

- Single muscle action approach: No indices were computed, instead all 16 items were regarded as separate variables.

\section{Pain and disability}

Pain as experienced by patients was assessed using a visual analogue scale (VAS; 0-100 mm), in which $0 \mathrm{~mm}$ represents no pain at all and $100 \mathrm{~mm}$ represents 'the worst pain I can imagine'. Patients were asked to rate their overall pain in the past week.

Observed disability was determined by watching video-taped performances of patients on a series of standardised tasks, using an adaptation of the method described by Keefe. ${ }^{26-28}$ An overall score for observed disability was calculated based on five items: three movement times (5-m walking time, stand-to-sit time and stand-torecline time), and two measures for the quality of the performance (level of guarding, level of rigidity). The overall-score for observed disability was constructed as follows. First, for the three movement times scores were transformed into 10 categories (each containing 10\% of scores), to correct for skewed distributions. Then z-scores were computed for all five items (movement times and qualitative assessments), to avoid weighting problems due to differences in score range between the items. These $\mathrm{z}$-scores were added up to obtain an overall-score for observed disability per patient. By definition, $z$-scores have a mean of 0 , which means that an overall score constructed from z-scores will also have a mean of 0 . A higher overall score means a higher level of disability. All items were scored by trained observers. This overall score has been shown to be internally consistent and valid. ${ }^{29}$ 
Next to observed disability, self-reported disability was also assessed. To this end, the mobility subscale of the IRGL was used. The IRGL (Influence of Rheumatic Disease on General Health and Lifestyle) is a Dutch adaptation of the Arthritis Impact Measurement Scales (AIMS) ${ }^{30}$ This subscale has seven items. Two items are general statements concerning disability in mobility, while the other five address disability in climbing stairs, riding a bicycle and walking. The IRGL is a 'positive' questionnaire, i.e. it measures 'ability' rather than 'disability'. To facilitate interpretation, scores on this test have been reversed to obtain a 'disability score'. After the reversal, the score range for this test is -28 (minimum disability) to -7 (maximum disability).

\section{Statistical analyses}

All analyses were performed using two subgroups of patients: one group comprising all patients with knee OA, and another group comprising all patients with hip OA. To assess the inter-relationships between the various muscle actions, first Pearson correlation coefficients were computed between all muscle actions. Next, factor analysis was performed. With the factor analysis, the unidimensionality of the pool of muscle actions could be assessed (i.e. can strength for a number of muscle actions be regarded as representations of the same entity, or should a clear distinction be made between, for instance, muscle strength around the hip and muscle strength around the knee?). The inclusion criterion for factors in this analysis was an eigenvalue $<1$.

The internal consistency of the several indices for muscle strength was assessed by computing Cronbach's $\alpha$. A value of 0.80 or more represents high internal consistency. ${ }^{31}$

Multiple regression analyses were performed with pain, observed disability and self-reported disability as dependent variables. The indices for muscle strength, which had been computed using various approaches (see above), were the independent variables. A separate analysis was performed for each combination of a dependent variable (i.e. pain or self-reported or observed disability) and an approach for computing indices for muscle strength (e.g. patient-based, joint-based). These regression analyses could establish the relationships between muscle strength on the one hand and pain and disability on the other hand.

All statistical analyses were carried out using SPSS version 8.0.

\section{RESULTS}

\section{Patient characteristics}

Table 1 shows the mean age and proportion of males and females in the study population, as well as raw item scores of the 16 muscle actions (corrected for the patient's body weight), mean sum-score on observed disability and selfreported disability, and mean pain-score for both the knee OA and hip OA groups.

\section{[ TABLE 1 ]}

\section{Inter-item relationships}

Pearson correlation coefficients between the 16 muscle actions for both subgroups are presented in Tables 2 and 3 . All coefficients are significantly greater than 0 ( $p<0.001$ for all coefficients). The highest correlations were found between the lateral and contralateral side of the same muscle action (e.g. flexion of the affected and unaffected hip). These correlations range from 0.74 to 0.88 in the hip OA group and 0.67 to 0.84 in the knee OA group. Correlations between two ipslateral muscle actions (e.g. flexion and extension of the affected hip) tend to be slightly higher than correlations between a lateral and different contralateral muscle action (e.g. flexion of the affected hip and extension of the unaffected hip).

\section{[ TABLES 2-3 ]}




\section{Internal consistency}

The internal consistency of the various indices was assessed computing Cronbach's $\alpha$. The results for both subgroups of patients are presented in Tables 4 and 5. Since the single muscle action approach does not use an index that consists of more than one item, this approach was not included in these analyses. The internal consistency is high for nearly all indices. Only the indices for muscle strength around the knee in the single joint approach scored below 0.80 , indicating satisfactory but not high internal consistency.

\section{[ TABLES 4-5 ]}

For both subgroups, factor analysis was also performed, to assess the unidimensionality of the complete set of muscle actions. For both the knee OA and hip OA groups, one factor was identified by the analysis. In the hip OA group, this factor accounted for $64.9 \%$ of variance between the items, with factor loadings of the separate muscle actions ranging from 0.75 to 0.89 . The results in the knee OA group were similar: the one factor accounted for $66.2 \%$ of variance, with factor loadings ranging from 0.76 to 0.89 .

\section{The relationship with pain and disability}

The results of the various multiple regression analyses are shown in Table 6 and 7 . These tables feature - for each approach separately - the fraction of variance accounted for $\left(r^{2}\right)$. In both groups, similar results are found for the various approaches. The strength of the relationship between observed disability and muscle strength ranges from 0.173 to 0.227 in the hip OA group and from 0.146 to 0.205 in the knee OA group. The same applies to self-reported disability $\left(\mathrm{r}^{2}\right.$ ranging from 0.136 to 0.174 in the hip OA group, and from 0.130 to 0.178 in the knee OA group). Only a minimal relationship could be established between pain and muscle strength. Again, no major differences were found between the various approaches in either of the two subgroups. In all cases, the relationship between muscle strength and pain and disability was a negative one: muscle weakness (i.e. lower muscle strength) was associated with more disability and, to a lesser extent, pain.

\section{[ TABLES 6-7 ]}

The analyses presented in this paper were also carried out without taking the actual location of OA into account. In these additional analyses, a distinction between left and right was made, instead of between affected and unaffected joints (e.g. for the single joint approach, separate indices were constructed for the left and right knee, rather than the affected and unaffected knee). The results of these additional analyses were remarkably similar to the results presented here. The results of these additional analyses can be found on the Internet, at http://www.nivel.nl/muscle/index.html.

\section{DISCUSSION}

Various approaches are available for the calculation of indices of muscle strength in patients with OA of the hip or knee. The goal of the present study was to determine which approach to the reduction of data into indices for muscle strength would provide the most useful and accurate set of indices. Such an approach would have the optimal trade-off between parsimony (as few indices as possible) and detail (no loss of vital information). To this aim, first the inter-relationships between the various muscle actions and the internal consistency of the indices for muscle strength were established. Next, the relationship of the various indices with pain and disability was established. With regard to the inter-relationships between muscle actions, the correlations showed that muscle strength for various actions is closely inter-related. As the factor analyses have shown, the strength of single muscle actions can be regarded as representations of one unidimensional construct. With respect to both the internal consistency and the relationship with pain and disability there were only minor differences between the indices resulting from various approaches. The internal consistency of the indices all reached an acceptable level. Also, in the regression analyses, the strength of the relationship between the indices of muscle strength and pain and disability was hardly influenced by the choice of approach. Isometric muscle strength is negatively associated with disability, in all of the approaches chosen. This 


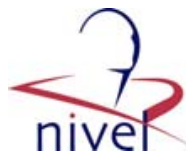

is consistent with earlier findings. ${ }^{9,14,15}$ Variations in muscle strength were found to account for some $15-20 \%$ of the variance in disability. In our opinion, the strength of the relationship between muscle weakness and disability (15-20\% variance-accounted-for) marks muscle weakness as an important entity within the multi-factorial framework of determinants of disability. No clear relationship was identified between pain and muscle strength. Muscle weakness was weakly associated with more pain, with muscle strength accounting for, on average, $5 \%$ of the variance in pain levels. A stronger relationship was expected to be found, and indeed has been found in an earlier study involving the same group of patients. ${ }^{32}$ In the present study, a substantial number of patients were excluded because they were diagnosed with bilateral OA. The resulting smaller group sizes, and therefore decreased statistical power, may be responsible for the inability of the present study to identify a clear relationship between muscle strength and pain.

The results seem to indicate that all of the aforementioned approaches are generally acceptable. For reasons of parsimony, approaches resulting in relatively few indices, such as the patient-based or averaged joint approach, may therefore be the best option. These approaches result in just one or two indices, which makes analysing and interpreting the results less complicated. The use of a patientbased approach is also consistent with the study by Zhang et al., ${ }^{33}$ who stated that when an overall assessment of a patient's level of functioning is made, only a patient-based analysis is appropriate. However, muscle strength was found to be significantly reduced around affected joints, compared with muscle strength around unaffected joints. This is also a common clinical finding in patients with OA, and should not be neglected. Therefore, the most suitable approach for reducing muscle strength data into indices is one that results in as few indices as possible, but with separate indices for muscle strength around affected and unaffected joints. Of course, the choice of which approach is most suitable depends on the specific design and aims of a given study. The present study has shown that each approach yields consistent indices, and that the manner in which data reduction is carried out does not interfere heavily with the outcomes of statistical analyses. In the context of research on the relationship between muscle strength and pain and disability in OA patients, it is concluded that the most suitable approach seems to be an approach which yields few indices, but with separate indices for muscle strength around affected and unaffected joints (i.e. the single joint approach).

For clinicians, whose interests may differ from those of researchers, these results may have other implications. Given the clear inter-relationships between various muscle actions, measuring a limited number of muscle actions will provide accurate information on a patient's overall level of muscle strength. The present study has shown that the same muscle actions on the ipsilateral and contralateral side are very closely related to each other, and that the entire pool of muscle actions around the knees and hips can be regarded as a unidimensional trait of the patient. Although closely associated, muscle strength around affected joints is generally decreased compared with muscle strength around unaffected joints. ${ }^{34}$ Overall, these findings suggest it is sufficient to assess a limited number of muscle actions.

\section{Clinical messages}

- Muscle strength is an important determinant of disability in OA of the knee or hip.

- Muscle strength can be regarded a trait at the level of the patient; all muscle strength around the knees and hips are closely interrelated.

- When assessing muscle strength in a clinical setting, it suffices to measure a limited number of muscle actions, as these will provide accurate information on a patient's level of muscle strength. 
Steultjens, M.P.M., Dekker, J., Baar, M.E. van, Oostendorp, R.A.B., Bijlsma, J.W.J.

Muscle strength, pain and disability in patients with osteoarthritis.

Clinical Rehabilitation: 15, 2001, nr. 3, p. 331-341

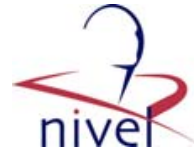

\section{TABLES}

Table 1 Patient characteristics

\begin{tabular}{|c|c|c|c|}
\hline & & Hip OA & Knee OA \\
\hline \multicolumn{2}{|l|}{$\begin{array}{l}\text { Number of patients } \\
\text { Demographics }\end{array}$} & 52 & 71 \\
\hline \multirow[t]{2}{*}{ Sex } & Female & $34(65.4 \%)$ & $57(80.3 \%)$ \\
\hline & Male & $18(34.6 \%)$ & $14(19.7 \%)$ \\
\hline \multicolumn{2}{|l|}{$\begin{array}{l}\text { Age (in years) } \\
\text { Weight (kg) }\end{array}$} & $\begin{array}{l}67.8 \pm 9.2 \\
76.2 \pm 11.3\end{array}$ & $\begin{array}{l}68.2 \pm 8.9 \\
78.1 \pm 11.8\end{array}$ \\
\hline \multicolumn{4}{|l|}{ Pain and disability } \\
\hline \multicolumn{2}{|c|}{ Overall pain in the past week $(0-100)$} & $39.4 \pm 25.8$ & $44.4 \pm 29.4$ \\
\hline \multicolumn{2}{|c|}{ Observed disability (composite $z$-score) } & $-0.18 \pm 0.99$ & $0.08 \pm 0.94$ \\
\hline \multicolumn{2}{|c|}{ Self-reported disability $(-7$ to -28$)$} & $-21.9 \pm 4.9$ & $-19.9 \pm 6.0$ \\
\hline \multicolumn{4}{|c|}{ Muscle strength $(\mathrm{N} / \mathrm{kg})$} \\
\hline \multirow[t]{2}{*}{ Hip flexion ${ }^{\mathrm{a}, \mathrm{b}}$} & Affected/ipsilateral & $2.22 \pm 0.81$ & $2.03 \pm 0.75$ \\
\hline & Not affected/contralateral & $2.50 \pm 0.82$ & $2.31 \pm 0.77$ \\
\hline \multirow[t]{2}{*}{ Hip extension } & Affected/ipsilateral & $1.64 \pm 0.81$ & $1.43 \pm 0.69$ \\
\hline & Not affected/contralateral & $1.72 \pm 0.72$ & $1.45 \pm 0.70$ \\
\hline \multirow[t]{2}{*}{ Hip internal rotation } & Affected/ipsilateral & $1.75 \pm 0.66$ & $1.57 \pm 0.57$ \\
\hline & Not affected/contralateral & $1.81 \pm 0.62$ & $1.68 \pm 0.58$ \\
\hline \multirow[t]{2}{*}{ Hip external rotation ${ }^{b}$} & Affected/ipsilateral & $1.40 \pm 0.43$ & $1.27 \pm 0.45$ \\
\hline & Not affected/contralateral & $1.46 \pm 0.39$ & $1.39 \pm 0.42$ \\
\hline \multirow[t]{2}{*}{ Hip adduction ${ }^{\mathrm{a}}$} & Affected/ipsilateral & $2.15 \pm 0.77$ & $1.75 \pm 0.73$ \\
\hline & Not affected/contralateral & $2.01 \pm 0.74$ & $1.82 \pm 0.72$ \\
\hline \multirow[t]{2}{*}{ Hip abductiona } & Affected/ipsilateral & $2.15 \pm 0.72$ & $2.28 \pm 0.82$ \\
\hline & Not affected/contralateral & $2.39 \pm 0.70$ & $2.34 \pm 0.80$ \\
\hline \multirow[t]{2}{*}{ Knee flexiona } & Ipsilateral/affected & $1.28 \pm 0.46$ & $1.15 \pm 0.42$ \\
\hline & Contralateral/not affected & $1.28 \pm 0.41$ & $1.22 \pm 0.42$ \\
\hline \multirow[t]{2}{*}{ Knee extensiona } & Ipsilateral/affected & $2.23 \pm 0.67$ & $2.03 \pm 0.69$ \\
\hline & Contralateral/not affected & $2.30 \pm 0.67$ & $2.27 \pm 0.72$ \\
\hline
\end{tabular}

aSignificant difference in muscle strength between affected and unaffected joint $(p<0.05)$.

bSignificant difference in muscle strength between ipsilateral and contralateral joint $(p<0.05)$.

Table 4 Internal consistency of indices of muscle strength in patients with hip OA

\begin{tabular}{lll}
\hline & $\begin{array}{l}\text { Number of } \\
\text { items per } \\
\text { index }\end{array}$ & Cronbach's $\alpha$ \\
\hline Patient-based & 16 & 0.97 \\
Averaged joint & & \\
$\quad$ Hip & 12 & 0.96 \\
$\quad$ Knee & 4 & 0.88 \\
Single joint & & \\
Hip affected & 6 & 0.91 \\
Hip not-affected & 6 & 0.92 \\
Knee ipsilateral & 2 & 0.75 \\
Knee contralateral & 2 & 0.74 \\
Averaged muscle action & & \\
Hip flexion & 2 & 0.87 \\
Hip extension & 2 & 0.91 \\
Hip external rotation & 2 & 0.87 \\
Hip internal rotation & 2 & 0.86 \\
Hip abduction & 2 & 0.90 \\
Hip adduction & 2 & 0.91 \\
Knee flexion & 2 & 0.92 \\
Knee extension & 2 & 0.87 \\
\hline
\end{tabular}

Table 5 Internal consistency of indices of muscle strength in patients with knee OA

\begin{tabular}{lll}
\hline & $\begin{array}{l}\text { Number of } \\
\text { items per } \\
\text { index }\end{array}$ & Cronbach's $\alpha$ \\
\hline Patient-based & 16 & 0.97 \\
Averaged joint & & \\
$\quad$ Knee & 4 & 0.90 \\
Hip & 12 & 0.96 \\
Single joint & & \\
Knee affected & 2 & 0.85 \\
Knee not-affected & 2 & 0.78 \\
Hip ipsilateral & 6 & 0.91 \\
Hip contralateral & 6 & 0.93 \\
Averaged muscle action & & \\
Knee flexion & 2 & 0.90 \\
Knee extension & 2 & 0.85 \\
$\quad$ Hip flexion & 2 & 0.91 \\
Hip extension & 2 & 0.89 \\
Hip external rotation & 2 & 0.89 \\
Hip internal rotation & 2 & 0.87 \\
Hip abduction & 2 & 0.91 \\
Hip adduction & 2 & 0.89 \\
\hline
\end{tabular}


Steultjens, M.P.M., Dekker, J., Baar, M.E. van, Oostendorp, R.A.B., Bijlsma, J.W.J.

Muscle strength, pain and disability in patients with osteoarthritis.

Clinical Rehabilitation: 15, 2001, nr. 3, p. 331-341

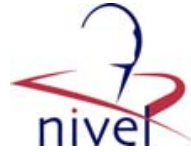

Table 6 Results of multiple regression analyses: fraction of variance accounted for per approach (hip OA)

\begin{tabular}{llll}
\hline & Observed disability & Self-reported disability & Pain \\
\hline Patient-based & 0.227 & 0.143 & 0.036 \\
Averaged joint & 0.218 & 0.148 & 0.039 \\
Single joint & 0.184 & 0.136 & 0.043 \\
Averaged muscle action & 0.195 & 0.142 & 0.029 \\
Single muscle action & 0.173 & 0.174 & 0.067 \\
\hline
\end{tabular}

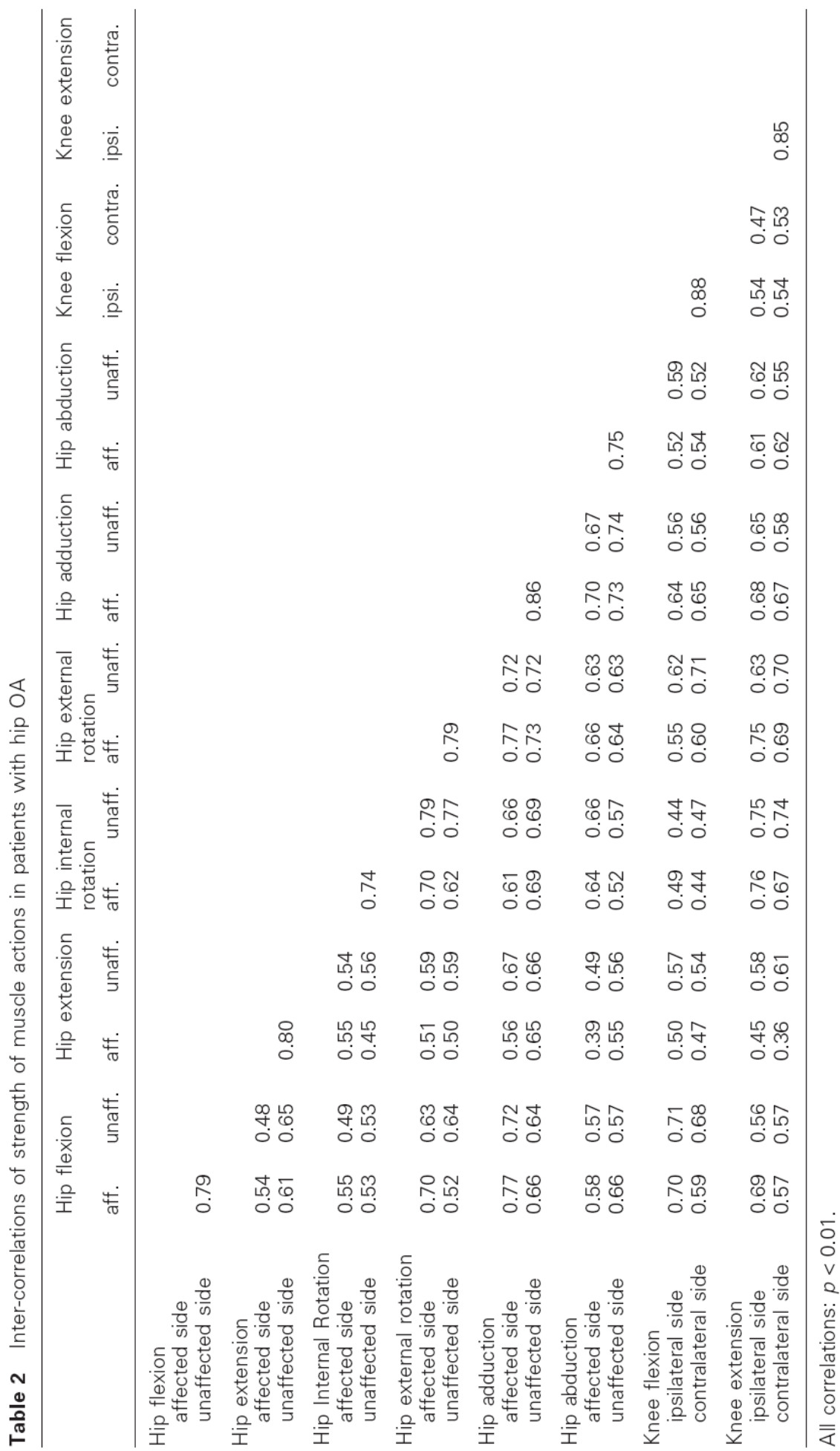


Steultjens, M.P.M., Dekker, J., Baar, M.E. van, Oostendorp, R.A.B., Bijlsma, J.W.J. Muscle strength, pain and disability in patients with osteoarthritis.

Clinical Rehabilitation: 15, 2001, nr. 3, p. 331-341

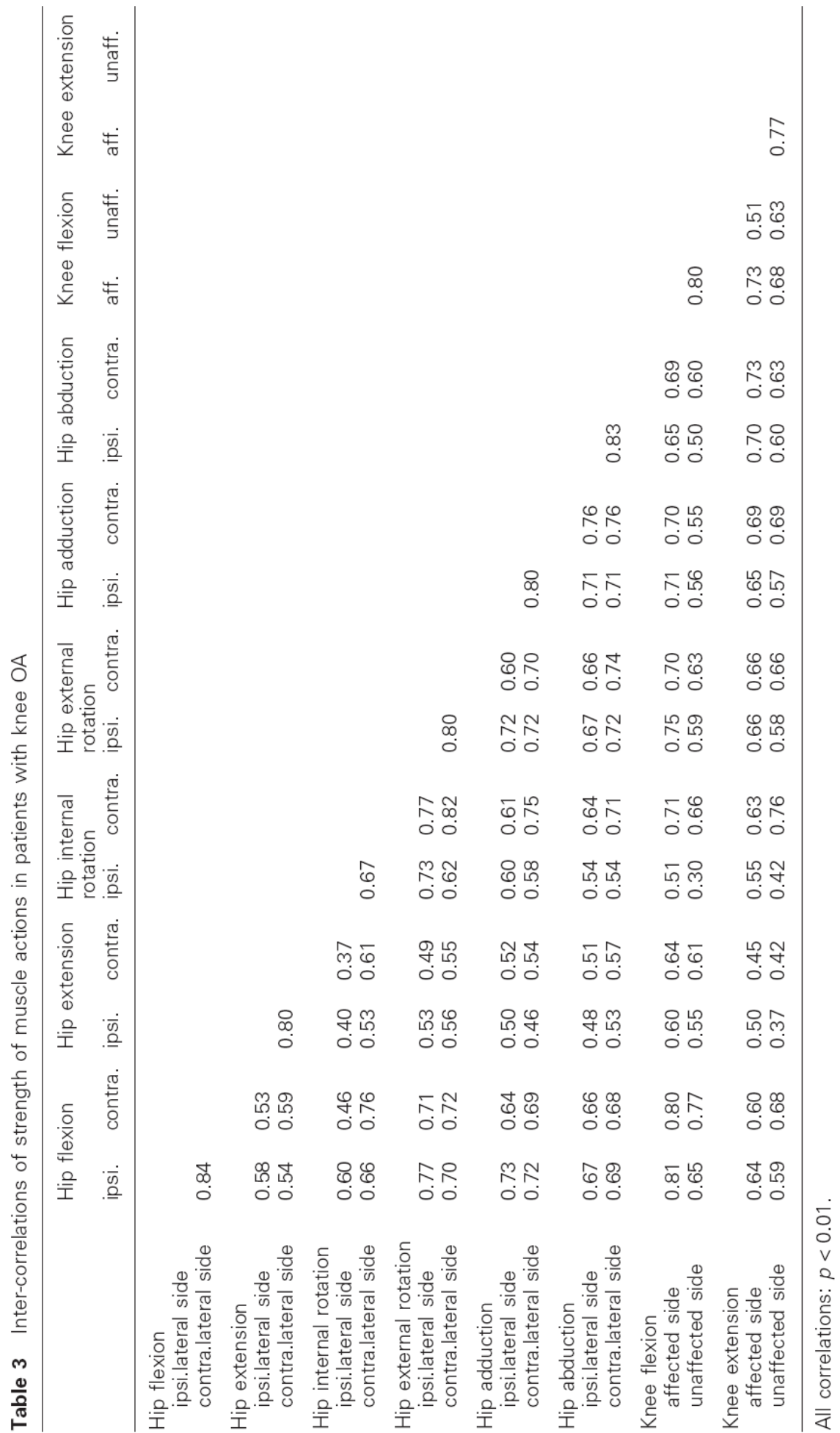

Table 7 Results of multiple regression analyses: fraction of variance accounted for per approach (knee OA)

\begin{tabular}{llll}
\hline & Observed disability & Self-reported disability & Pain \\
\hline Patient-based & 0.205 & 0.178 & 0.025 \\
Averaged joint & 0.205 & 0.177 & 0.042 \\
Single joint & 0.185 & 0.165 & 0.056 \\
Averaged muscle action & 0.146 & 0.130 & 0.053 \\
Single muscle action & 0.202 & 0.177 & 0.057 \\
\hline
\end{tabular}


Steultjens, M.P.M., Dekker, J., Baar, M.E. van, Oostendorp, R.A.B., Bijlsma, J.W.J.

Muscle strength, pain and disability in patients with osteoarthritis.

Clinical Rehabilitation: 15, 2001, nr. 3, p. 331-341

\section{REFERENCES}

1. Nordesjö L-O, Nordgren B, Wigren A, Kolstad K. Isometric strength and endurance in patients with severe rheumatoid arthritis or osteoarthritis in the knee joints. Scand J Rheumatol 1983; 12: 15256.

2. Ekdahl C, Andersson SI, Svensson B. Muscle function of the lower extremities in rheumatoid arthritis and osteoarthritis - a descriptive study of patients in a primary health care district. J Clin Epidemiol 1989; 42: 947-54.

3. Messier SP, Loeser RF, Hoover JL, Semble EL, Wise CM. Osteoarthritis of the knee: effects on gait, strength, and flexibility. Arch Phys Med Rehabil 1992; 73: 29-36.

4. Hall KD, Hayes KW, Falconer J. Differential strength decline in patients with osteoarthritis of the knee: revision of a hypothesis, Arthr Care Res 1993; 6: 89-96.

5. Tan J, Balci N, Sepici V, Gener, FA. Isokinetic and isometric strength in osteoarthritis of the knee: a comparative study with healthy women. Am J Phys Med Rehabil 1995; 74: 364-69.

6. Wessel J. Isometric strength measurements of knee extensors in women with osteoarthritis of the knee. J Rheumatol 1996; 23: 328-31.

7. Lankhorst GJ, Van De Stadt RJ, Van Der Korst JK. The relationships of functional capacity, pain and isometric and isokinetic torque in osteoarthrosis of the knee. Scand J Rehab Med 1985; 17 : 167-72.

8. Dekker J, Boot B, Van Der Woude LHV, Bijlsma JWJ. Pain and disability in osteoarthritis: a review of biobehavioral mechanisms. J Behav Med 1992; 15: 189-214.

9. McAlindon TE, Cooper C, Kirwan JR, Dieppe PA. Determinants of disability in osteoarthritis of the knee. Ann Rheum Dis 1993; 52: 258-62.

10. Dekker J, Tola P, Aufdemkampe G, Winckers M. Negative affect, pain and disability in osteoarthritic patients: the mediating role of muscle weakness. Behav Res Ther 1993; 31: 203206.

11. Madsen OR, Bliddal H, Egsmose C, Sylvest J. Isometric and isokinetic quadriceps strength in gonarthrosis; inter-relations between quadriceps strength, walking ability, radiology, subchondral bone density and pain. Clin Rheumatol 1995; 14: 308-14.

12. Dekker J, Mulder PH, Bijlsma JWJ, Oostendorp RAB. Exercise therapy in patients with rheumatoid arthritis and osteoarthritis: a review. Adv Behav Res Ther 1993; 15: 211-38.

13. Hurley MV, Scott DC. Improvements in quadriceps sensorimotor function and disability of patients with knee osteoarthrits following a clinically practicable exercise regime. $\mathrm{Br} \mathrm{J}$ Rheumatol 1998; 37: 1181-87.

14. Slemenda C, Brandt KD, Heilman DK. Quadriceps weakness ans osteaoarthritis of the knee. Ann Intern Med 1997; 127: 97-104.

15. Chandler JM, Duncan PW, Kochersberger G, Studenski S. Is lower extremity strength gain associated with improvement in physical performance and disability in frail community-dwelling elders? Arch Phys Med Rehabil 1998; 79: 24-30.

16. Baar ME van, Dekker J, Oostendorp RAB et al. The effectiveness of exercise therapy in patients with osteoarthritis of knee or hip: a randomised clinical trial. J Rheumatol 1998; 25: 2432-39.

17. Altman R, Asch E, Bloch D et al. Development of criteria for the classification and reporting of osteoarthritis: classification of osteoarthritis of the knee, Arthritis Rheum 1986; 29: 1039-49.

18. Altman R, Alarcon G, Appelrouth $D$ et al. The American College of Rheumatology criteria for the classification and reporting of osteoarthritis of the hip. Arthritis Rheum 1991; 34: 505-14 .

19. Bohannon RW. Muscle strength testing with hand-held dynamometers. In: Amundsen LR ed. Muscle strength testing: instrumented and noninstrumented systems. New York: Churchill Livingstone, 1990: 69-88.

20. Bohannon RW. Test-retest reliability of hand-held dynamometry during a single session of strength assessment. Phys Ther 1986; 66: 206-209.

21. Bohannon RW, Andrews AW. Interrater reliability of hand-held dynamometry. Phys Ther 1987; 67: 931-33.

22. Wadsworth CT, Krishnan R, Sear M. Intrarater reliability of manual muscle testing and hand-held dynamometric muscle testing. Phys Ther 1987; 67: 1342-47.

23. McMahon LM, Burdett RG, Whitney SL. Effects of muscle group and placement site on reliability of hand-held dynamometry strength measurements. J Orthop Sports Phys Ther 1992; 15: 236-41.

24. Bohannon RW. Make tests and break tests of elbow flexor muscle strength. Phys Ther 1988; 68: 931-33.

25. Kendall $\mathrm{H}$, Kendall $\mathrm{F}$, Wadsworth $\mathrm{G}$. Muscle testing and function, second edn. Baltimore: Williams and Wilkins, 1971. 
Steultjens, M.P.M., Dekker, J., Baar, M.E. van, Oostendorp, R.A.B., Bijlsma, J.W.J.

Muscle strength, pain and disability in patients with osteoarthritis.

Clinical Rehabilitation: 15, 2001, nr. 3, p. 331-341

26. Keefe FJ, Block AR. Development of an observational method for assessing pain behavior in chronic low back patients. Behav Ther 1982; 13: 363-75.

27. Dekker J, Tola P, Aufdemkampe G, Winckers M. Categories of pain behaviour in osteoarthritis patients. Physiother Theory Pract 1993; 9: 157-63.

28. Baar ME van, Dekker J, Lemmens JAM, Oostendorp RAB, Bijlsma JWJ. Pain and disability in patients with osteoarthritis of hip or knee: the relationships with articular, kinesiological and psychological characteristics. J Rheumatol 1998; 25: 125-33.

29. Steultjens MPM, Dekker J, Baar ME van, Oostendorp RAB, Bijlsma JWJ. Consistency and validity of an observational method for assessing disability in mobility in patients with osteoarthritis. Arthr Care Res 1999; 12: 19-25.

30. Huiskes CJAE, Kraaimaat FW, Bijlsma JWJ. De ontwikkeling van de IRGL: een instrument omgezondheid te meten bij patienten met reuma [Development of the IRGL: an instrument for measuring health status in patients with arthritis].Gedrag en Gezondheid 1990; 18: 78-89.

31. Cronbach LJ. Coefficient alpha and the internal structure of tests. Psychometrika 1951; 16: 297335.

32. Baar ME van, Dekker J, Lemmens JAM, Oostendorp RAB, Bijlsma JWJ. Pain and disability in patients with osteoarthritis of hip or knee: the relationship with articular, kinesiological and psychological characteristics. J Rheumatol 1998; 25: 125-33.

33. Zhang Y, Glynn RJ, Felson DT. Musculoskeletal research: should we analyze the joint or the person? J Rheumatol 1996; 23: 1130-34.

34. Miller R, Kettelkamp DB, Laubenthal KN, Karagiorgos A, Smidt GL. Quantitative correlations in degenerative arthritis of the knee. J Bone Joint Surgery 1973; 55A: 956-962. 